\title{
A história natural do Grupo Serra Geral desde o Cretáceo até o Recente
}

\author{
The natural history of the Serra Geral Group between the Cretaceous and the \\ Holocene
}

\author{
Léo Afraneo Hartmann *1 \\ ${ }^{1}$ Instituto de Geociências, Universidade Federal do Rio Grande do Sul, Porto Alegre, Brasil
}

\begin{abstract}
Resumo
A história natural do Grupo Serra Geral abrange muitos aspectos, desde a fusão parcial do manto astenosférico, a ascensão e modificação dos magmas e efusão das lavas. Inclui também a interação dos magmas com a crosta, principalmente o aquecimento do aquífero Guarani e o pirometamorfismo das formações sedimentares da Bacia do Paraná. A história culmina com a geração hidrotermal e intempérica de sílica gossans sobre jazidas de geodos de ametista, ficando registrados na lama dos gossans a evolução das espécies e do clima nos últimos 10.000 anos. Além dos processos magmáticos usualmente estudados, está identificado o processo de geração de paralavas por queima de metano, aquecendo a $1.800{ }^{\circ} \mathrm{C}$ e refundindo basaltos que se encontravam a $1.000{ }^{\circ} \mathrm{C}$. Nessa refusão, podem ser gerados depósitos de Au-EGP-Cu em complexos estratiformes. O hidrotermalismo causou o preenchimento de amígdalas com zeolitas e esmectita, possibilitando o uso do basalto em rochagem. Também são hidrotermais as jazidas de ametista e ágata. O cobre nativo foi depositado no final do primeiro evento hidrotermal. No segundo evento hidrotermal, foi injetada água quente e vapor, contendo areia. A história natural do grupo vulcânico está assim melhor entendida; seu estudo exige a descrição de muitos aspectos da dinâmica do planeta, no seu interior e na superfície.
\end{abstract}

Palavras-chave: Grupo Serra Geral, Cretáceo, História natural, Vulcanismo.

\begin{abstract}
The natural history of the Serra Geral Group comprises a series of processes, starting with the partial melting of the asthenosphere, continuing with the upwelling and modification of magmas and reaching the effusion of the basalt lavas. It also includes interaction of these magmas with the surrounding crust, especially causing heating of the Guarani aquifer and pyrometamorphism of the sedimentary units of the Paraná Basin. This evolution culminates with the hydrothermal alteration and weathering of silica gossans over amethyst geode zones, recording in the gossans' mud the local evolution of life and climate in the last 10 thousand years. Besides the well-studied magmatic processes, the distinctive formation of paralavas related with methane combustion was identified, including re-melting of basalts at around $1.800^{\circ} \mathrm{C}$. The re-melting may generate Au-EGP-Cu ore deposits in stratiform complexes. Hydrothermal alteration caused the filling of amygdales with zeolites and smectite, allowing the use of such basalts in the 'rock for crops' practice. Gem-quality amethyst and agate deposits are also hydrothermal in origin, as well as native copper (first hydrothermal event) and sand injections (second hydrothermal event). The natural history of the volcanic group is thus better understood; its study demands the description of many aspects of the planet's dynamics, both in its interior and at the surface.
\end{abstract}

Keywords: Serra Geral Group, Cretaceous, Natural history, Volcanism.

\footnotetext{
*leo.hartmann@ufrgs.br

Recebido: 20/03/2014 Aceito: 20/03/2014
} 


\section{Introdução}

$\mathrm{O}$ Grupo Serra Geral é uma unidade geológica que desperta grande interesse no meio científico e também na sociedade em geral, pois tem grande extensão (próximo a $1.000 .000 \mathrm{~km}^{2}$ ) e grande espessura (500-1.000 m na maior parte), é repositório de jazidas de geodos de ametista de classe mundial, possui tipos de rochas variados e mesmo algumas especiais, além de apresentar um grande potencial de bens minerais (ouro, elementos do grupo da platina e cobre) a serem descobertos. Apesar de sua grande extensão e volume, a formação do grupo vulcânico não causou extinção significativa de espécies. O grupo foi gerado em clima árido, mas recentemente foram formados sílica gossans

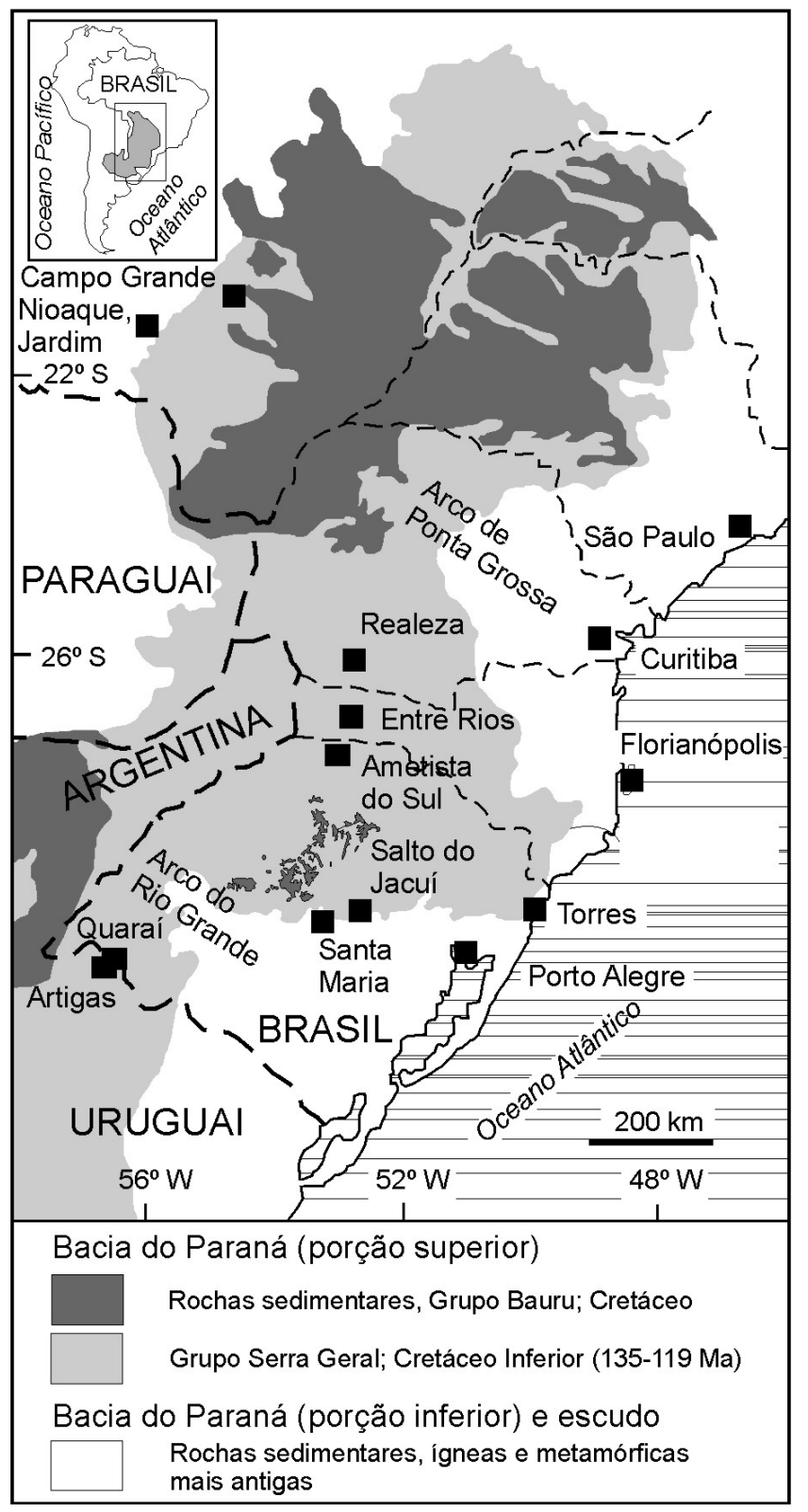

Figura 1. Mapa geológico do Grupo Serra Geral. sobre jazidas de gemas e metais em clima úmido.Os estudos foram realizados durante 10 anos, atingindo várias partes do grupo (Fig. 1), como o distrito gemológico Los Catalanes (Artigas, Uruguai), os distritos mineiros de Ametista do Sul, Salto do Jacuí e Quaraí e outras regiões do Rio Grande do Sul, o distrito mineiro de Entre Rios (Santa Catarina), a região de Realeza (Paraná) e as regiões de Campo Grande e Nioaque (Mato Grosso do Sul). Dessa forma, foram estudadas as relações geológicas do grupo próximo ao contato basal com a Formação Botucatu (Quaraí, Novo Hamburgo e Torres, Rio Grande do Sul; Nioaque, Mato Grosso do Sul) e no depocentro da Bacia do Paraná (Ametista do Sul, Entre Rios e Realeza). Com isso, os principais aspectos da história natural do grupo foram avaliados e são aqui apresentados.

\section{Metodologia}

O conceito de referência para todos os estudos feitos no grupo vulcânico foi o foco na unidade geológica básica, que é o derrame. A metodologia inicial consistiu em desenvolver critérios de campo, incluindo gama -espectrometria, para a identificação de cada derrame presente na área de estudo. Análises químicas de rochas foram realizadas no laboratório ACME (Canadá) para a identificação de cada derrame. Cada afloramento foi visitado no mínimo duas vezes, inicialmente para a descrição dos derrames, medidas de contagens por segundo (cps) com cintilômetro (número mínimo de 10 leituras em cada afloramento) e coleta de amostras de rochas. Para testar a variabilidade química horizontal e vertical dos derrames presentes, várias análises químicas e muitas medidas de cintilometria foram realizadas no mesmo derrame. Após a obtenção das análises químicas e sua interpretação, o mesmo afloramento foi visitado novamente. Com isso, a estratigrafia dos derrames foi estabelecida em cada região estudada e a cintilometria passou a ser utilizada no campo para a identificação de cada derrame, pois os valores de cps dos derrames foram calibrados com as análises químicas de amostras do mesmo local.

A metodologia de estudo iniciou com a interpretação de imagens de satélite em todas as áreas estudadas, seguido de trabalho de geologia de campo, incluindo cintilometria, e coleta de amostras. Foram estudadas lâminas petrográficas das rochas vulcânicas e realizado o imageamento de elétrons retroespalhados e catodoluminescência, além de análises químicas dos minerais por microssonda eletrônica. Isótopos estáveis de $\mathrm{S}$ e O foram investigados em rochas e minerais.

Além dos laboratórios da Universidade Federal do Rio Grande do Sul, foram utilizados laboratórios da Universidade de Stuttgart e Universidade de Western Australia. Várias teses de doutorado, dissertações de mestrado e trabalhos de conclusão de curso de geologia foram realizados ao longo dos estudos. 


\section{Geologia geral}

O Grupo Serra Geral cobre $917.000 \mathrm{~km}^{2}$ da região sudeste da América do Sul e é comumente incluído na província vulcânica Paraná, que possui o fragmento de Etendeka ( $1 \%$ da área total da província) na África. A espessura máxima do grupo é de $1.755 \mathrm{~m}$, medida em furo de sonda no sudoeste de São Paulo, havendo grandes extensões com 500-1.000 m no depocentro da Bacia do Paraná (Wildner et al., 2006). A bacia tem o grupo vulcânico próximo ao seu topo, somente coberto pelo Grupo Bauru de rochas sedimentares e pequeno volume de rochas vulcânicas alcalinas. A espessura total antes da erosão é estimada em $5.000 \mathrm{~m}$ próximo à costa atlântica e $3.000 \mathrm{~m}$ no interior do continente.

A presença de um grande volume de rochas basálticas intrusivas na crosta, sob o grupo vulcânico, é postulado (Mariani et al., 2013) para justificar os dados gravimétricos obtidos por satélite. Dessa forma, pode haver $10.000 \mathrm{~m}$ de sills basálticos intrusivos nas rochas sedimentares da Bacia do Paraná e no embasamento siálico subjacente. Esses sills devem ser o equivalente intrusivo da maior parte das lavas presentes em superfície. O seu esfriamento foi a origem do calor necessário para a alteração derrame-a-derrame dos basaltos.

As rochas vulcânicas dominantes (95 vol.\%) são basalto, andesito basáltico e andesito, seguidas de riodacito e pouco riolito (5 vol.\%). As rochas são afíricas, geralmente microporfiríticas, sendo alguns riodacitos do tipo Chapecó porfiríticos com fenocristais $(1 \mathrm{~cm})$ de plagioclásio. Devido a isso, é necessária a realização de análises químicas ou medidas cintilométricas para a identificação dos derrames.

Ao longo de toda a extensão e estratigrafia do grupo vulcânico, há camadas de arenito silicificado ( 0,5 a 5,0 $m$ de espessura, 100-500 $m$ de comprimento) entre derrames de basalto. Em algumas seções, o volume total de arenito é muito baixo. Esses arenitos são interpretados como injetitos de areia (Duarte et al., 2012; Hartmann et al., 2013b).

O maior volume de lavas foi extrusionado em torno de 134,5 Ma (Pinto et al., 2011; Janasi et al., 2011), mas o vulcanismo teve manifestações em tempo mais prolongado até $129 \mathrm{Ma}$ (Brückmann et al., 2013).

A grande maioria dos derrames da província vulcânica são do tipo pahoehoe (Waichel et al, 2006), com estrutura de crosta inferior e superior intensamente amigdaloidais, e núcleo maciço. Poucos derrames são do tipo aa, em que a lava possui crosta superior (eventualmente também a inferior) constituída de fragmentos angulosos (clinker) e núcleo maciço (Hartmann et al., 2010). O processo de efusão de lava pahoehoe consiste no avanço de lobos, que podem se sobrepor; esse conjunto de lobos constitui um campo de derrames (Vye-Brown et al., 2013), que é a unidade básica do vulcanismo mas ainda não foi descrito no Grupo Serra Geral. O conceito de derrame utilizado neste estudo corresponde a um campo de derrames.
Há uma zonalidade de distribuição de rochas vulcânicas alto-Ti na porção norte da província vulcânica Paraná e baixo-Ti na porção sul, mas há exceções em algumas partes. São reconhecidos seis tipos químicos de lavas (Peate et al., 1992), mas Licht e Arioli (2012) sugerem a existência de um número maior de tipos químicos com base em tratamento estatístico de grande número de análises químicas de rochas vulcânicas do grupo. Como cada derrame do Grupo Serra Geral possui composição química particular e sem repetição na estratigrafia, o número de tipos químicos pode ser muito alto. A caracterização de um tipo químico de lava é um resultado do tipo de parâmetro químico utilizado. Devido a essa diversidade química, cada derrame pode ser considerado um tipo químico, ou seja, o Grupo Serra Geral é constituído por muitos tipos químicos de lava. Para muitos objetivos, a divisão em seis grupos químicos é suficiente.

O Grupo Serra Geral é o maior produtor mundial (400 t/mês) de geodos de ametista, principalmente em Ametista do Sul, mas também em Artigas e outras regiões. Grandes falhas transcorrentes cortam as rochas vulcânicas, geralmente relacionadas com os esforços da abertura inicial do Oceano Atlântico.

\section{A geração do grupo}

Diferentes processos geraram as lavas basálticas e as riodacíticas. Um estudo de referência para o magmatismo é Marsh (2013). Os magmas basálticos são provenientes do manto, por fusão parcial. Após a fusão, os líquidos ascenderam através do manto astenosférico e do manto litosférico, estabelecendo câmaras magmáticas dentro da crosta até atingir a superfície. Processos diversos atuaram para a diversificação dos tipos de líquidos que atingiram a superfície. Isso inclui o tipo de manto, considerado como sendo litosférico no início do magmatismo (base da coluna estratigráfica) e evoluindo para astenosférico em seguida. No entanto, a interpretação de isótopos de Os (Rocha-Júnior et al., 2012) parece indicar o predomínio de manto astenosférico na geração dos líquidos basálticos. O mecanismo mais provável é a presença de uma pluma de manto profundo sob a litosfera; sua fusão gerou os magmas. Parece enfraquecida a hipótese de fusão do manto por superaquecimento da litosfera sob o supercontinente Gondwana.

Os riodacitos constituem extensas $(50-100 \mathrm{~km})$ camadas com espessura homogênea e estrutura interna maciça. Por isso, são também considerados derrames de lava. A hipótese mais consistente de origem é o fracionamento de líquidos basálticos em câmaras magmáticas na crosta e posterior efusão na superfície.

A espessura dos derrames de basalto pahoehoe na província vulcânica Paraná é de 10-80 m, com extensão atingindo $100 \mathrm{~km}$. Essa grande extensão só pode ser alcançada por um derrame devido ao isolamento tér- 
mico da crosta superior e inferior da lava. Essa crosta consolida e possibilita o deslocamento de lava líquida no seu interior (túneis de lava), sem perda de calor. Lavas aa alcançam extensões menores (10-20 km), pois não possuem essa camada isolante bem desenvolvida.

Como resultado, o Grupo Serra Geral pode ser visto como um conjunto de mais de 100 derrames em cada seção, em que cada derrame é considerado equivalente a um campo de derrames. Esses derrames possuem extensões de 1-100 km ou mais, com arquitetura de interdigitação com derrames de outras seções vizinhas até alcançar $2.000 \mathrm{~km}$, que é a distância entre o sul do Uruguai e Mato Grosso. A metodologia de correlação dos derrames em longa distância, com uso integrado de estratigrafia, geoquímica de rochas e gamaespectrome-
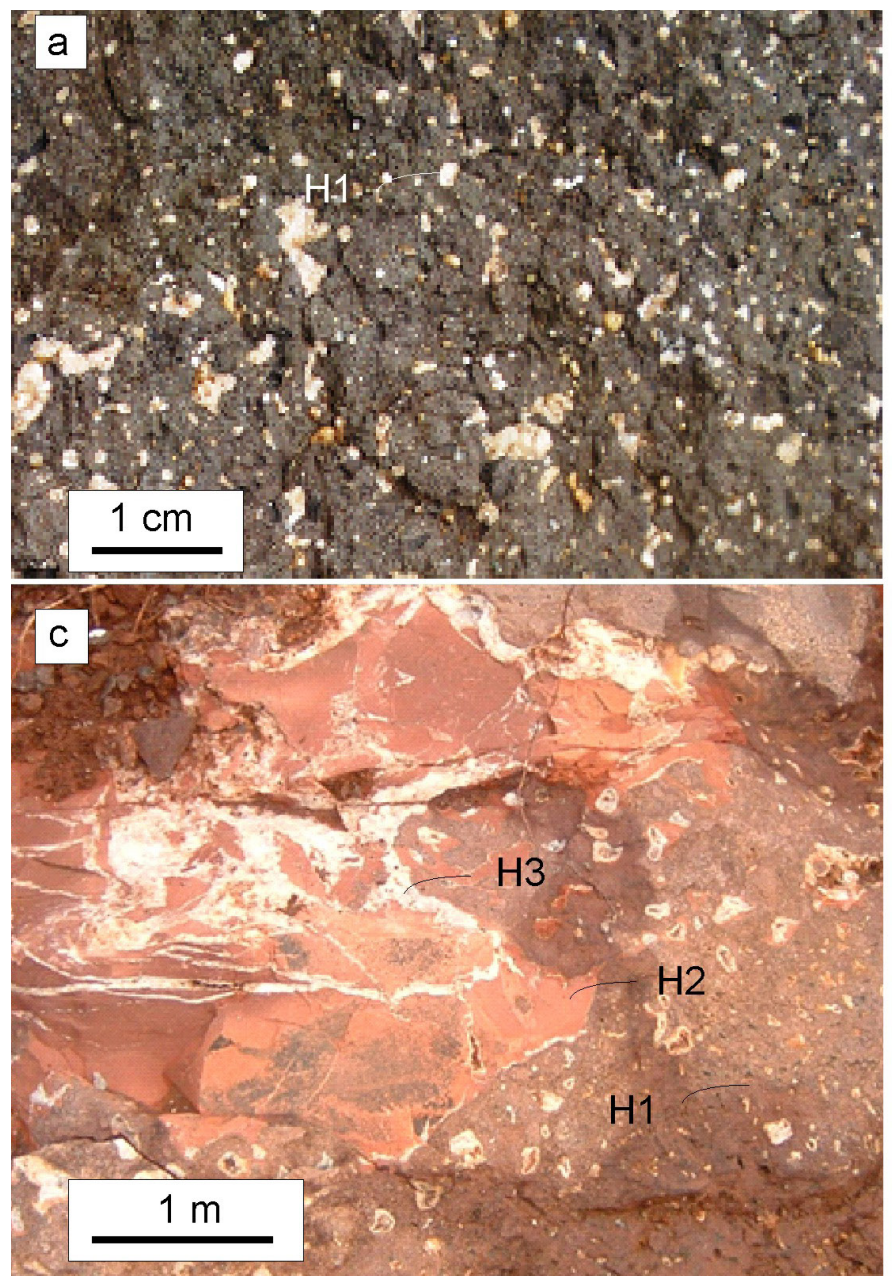

tria, foi estabelecida no grupo vulcânico por Hartmann et al. $(2010 ; 2013 a, b)$.

\section{Os eventos geológicos mais significativos}

O Grupo Serra Geral foi formado através de uma sequência de eventos, cada um abrangendo grande complexidade. O entendimento da sequência possibilita a sua descrição como evento magmático $\mathrm{M}$, evento paralavas $\mathrm{P}$, três eventos hidrotermais $\mathrm{H} 1, \mathrm{H} 2$ e H3, grandes falhamentos F e formação de sílica gossans G. Alguns desses processos estão documentados nas Figuras 2, 3 e 4. O evento $\mathrm{M}$ tem sido estudado sistematicamente e não será detalhado aqui.
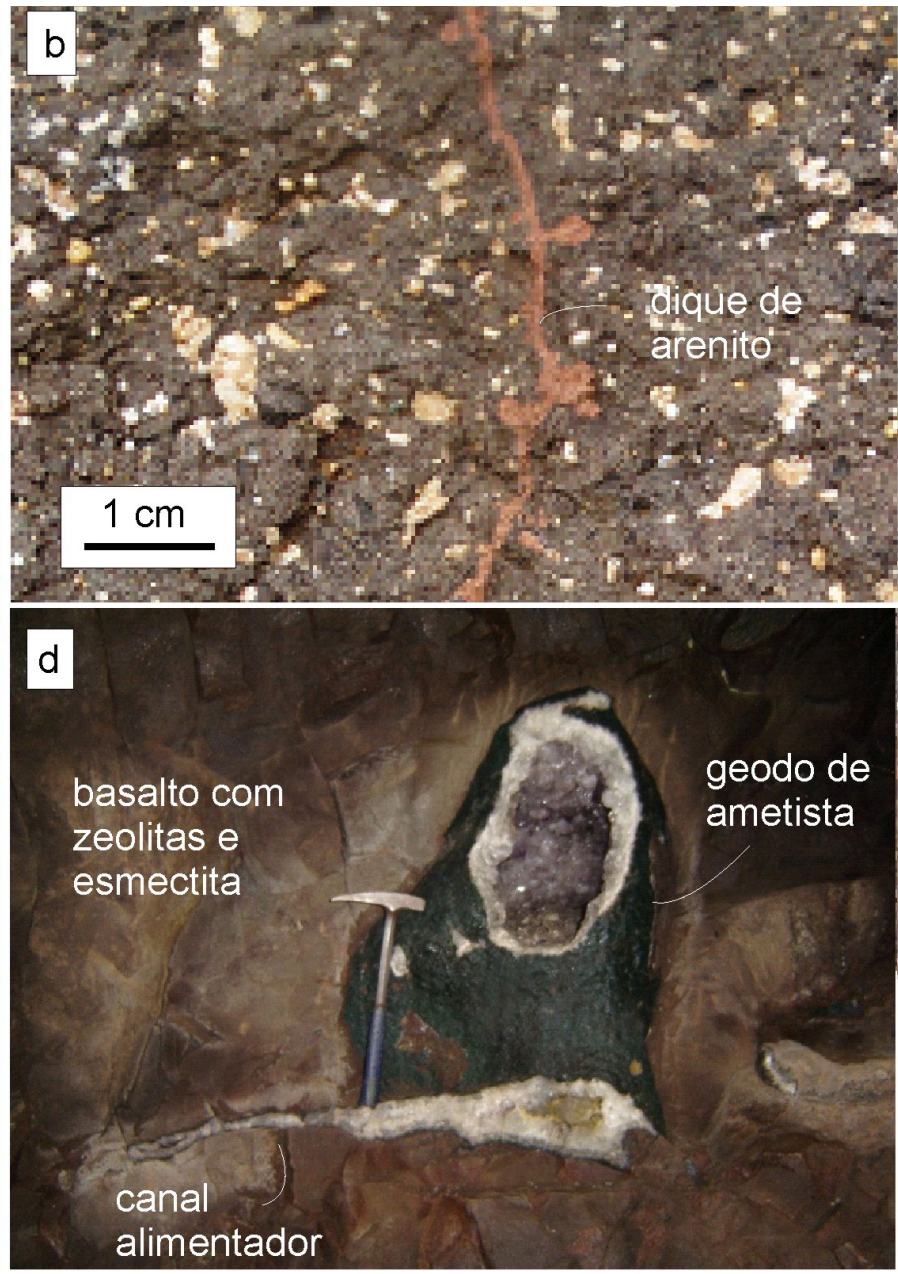

Figura 2. Documentação fotográfica dos eventos hidrotermais do Grupo Serra Geral. (a) Evento H1 de preenchimento das amígdalas por zeolitas e minerais de argila. Foto na estrada de acesso à Serra do Faxinal, próximo a Torres, RS. (b) Evento H2 de injeção de água contendo areia fluidizada, registrado na forma de dique de arenito silicificado. A água dissolveu os minerais secundários de H1 de algumas amígdalas e depositou areia. Foto na estrada de acesso à Serra do Faxinal, próximo a Torres, RS. (c) A foto registra os três eventos hidrotermais em corte de estrada próximo a Três Passos. H1 foi o processo de preenchimento de amígdalas; H2 foi a injeção explosiva de água quente contendo areia fluidizada, agora presente como um stockwork de arenito silicificado; H3 foi o processo de dissolução dos grãos de quartzo da areia e a reprecipitação em stockwork de quartzo. (d) Evento H3 de injeção explosiva de água quente e vapor e geração de cavidades. O registro é a fratura inclinada, que foi o canal alimentador do geode de ametista. Mina do Museu, Ametista do Sul. 

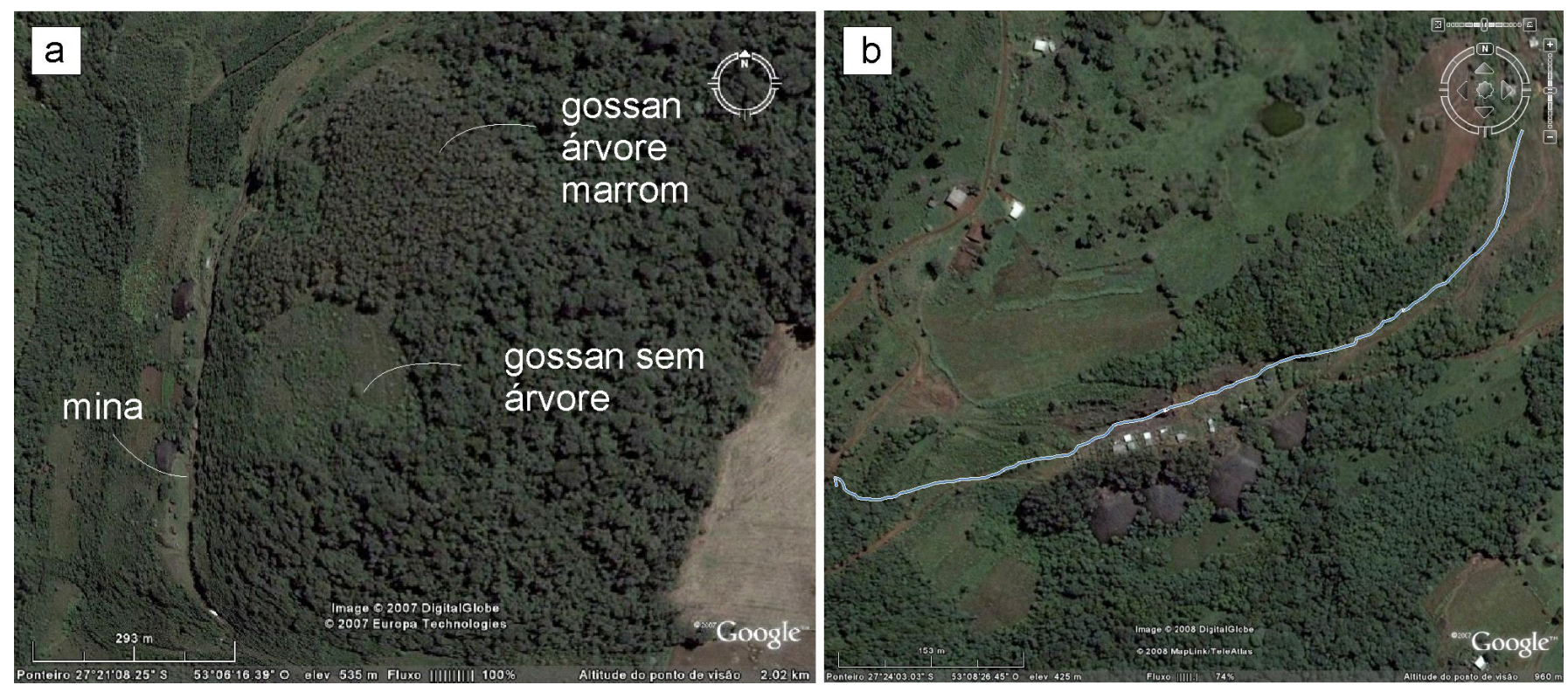

Figura 3. Imagens de satélite de sílica gossans no distrito mineiro de Ametista do Sul. (a) Mata Atlântica tem coloração marrom no gossan menos desenvolvido (mineralização pobre), e não está implantada no gossan mais desenvolvido (mineralização rica). (b) Linha de vertentes indicada; fica localizada no nível do piso das galerias subterrâneas. Corresponde à fratura horizontal que alimentou a formação dos geodos.
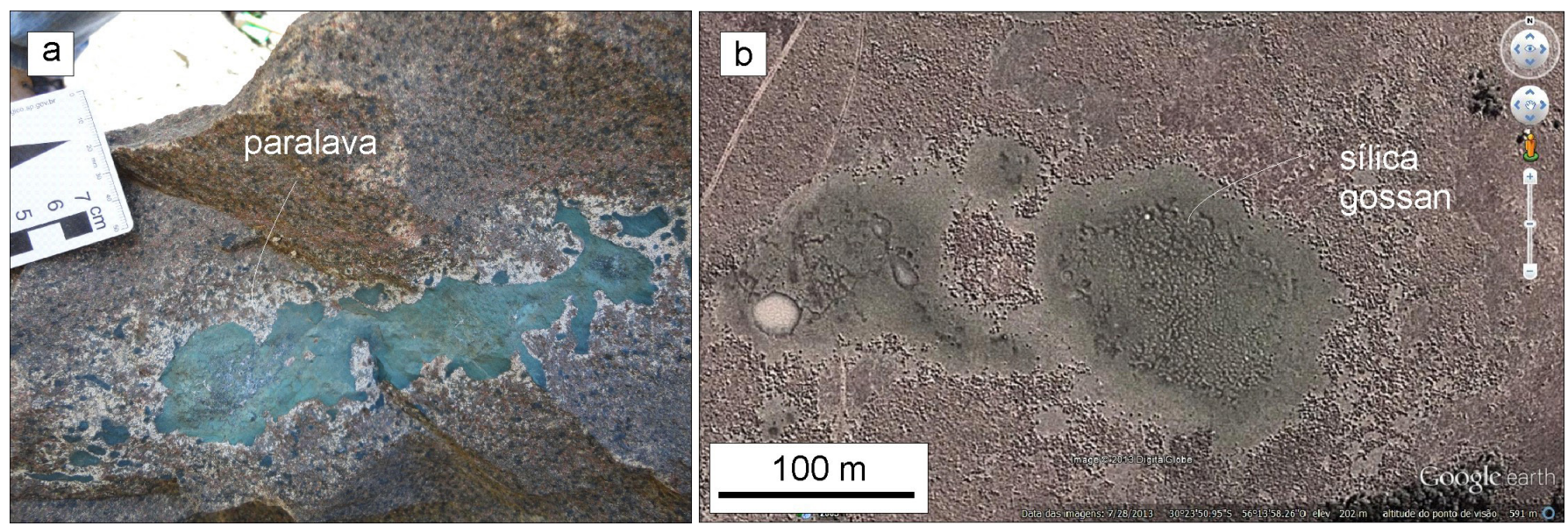

Figura 4. (a) Processo de geração de paralavas registrado no seu início, com um resíduo de reação (agora principalmente celadonita) em contato com a paralava (cinza claro) e o basalto protólito. (b) Sílica gossan em Quaraí, Rio Grande do Sul. O tom verde mais intenso da grama dentro do hexágono contrasta com a grama mais cinza do lado de fora. Lago natural presente no gossan.

O evento paralavas $\mathrm{P}$ consistiu em diversificado processo, envolvendo matéria orgânica, sills, gás, refusão de lava e geração de minérios. A quebra de querogênio (principalmente tipo III) da Formação Ponta Grossa e Formação Irati foram o primeiro processo, causado pela intrusão de sills basálticos, seguido da ascensão do metano e sua ignição espontânea a $1.000{ }^{\circ} \mathrm{C}$. A espessura integrada dos sills intrusivos nas rochas das formações é superior à espessura das duas formações. $\mathrm{O}$ enorme volume de gás metano gerado ascendeu na Bacia do Paraná em temperatura inferior àquela exigida para a ignição espontânea (superior a $600^{\circ} \mathrm{C}$ ). Ao alcançar a base do núcleo maciço da lava basáltica mais recente, que está a cerca de $1.000^{\circ} \mathrm{C}$, o metano entra em combustão espontânea. Isso significa que cada molécula de gás reage com o oxigênio dos minerais presentes (piroxênios, plagioclásio, magnetita, ilmenita, apatita). Esse processo é altamente exotérmico, elevando a temperatura local até $1.800{ }^{\circ} \mathrm{C}$ e refundindo o recém-cristalizado basalto. O resíduo da fusão inclui minerais como ferro nativo e grafite, ainda não identificados no grupo mas comuns em ambientes similares de outras regiões. O líquido neoformado injeta o derrame-mãe e fica registrado como diques e sills de paralavas, rochas que apresentam longos $(10 \mathrm{~cm})$ cristais de clinopiroxênio, plagioclásio, magnetita e apatita em matriz vítrea. Essas rochas, anteriormente designadas de pegmatitos, são comuns no depocentro da Bacia do Paraná, onde compõem pequena expressão 
volumétrica dos derrames.

As paralavas foram formadas dentro do derrame espesso, antes da formação de colunas de esfriamento a $900{ }^{\circ} \mathrm{C}$. Em derrames mais finos que $20 \mathrm{~m}$, o volume de paralavas é muito pequeno, geralmente zero. Isso é devido ao curto tempo em que a lava permaneceu a $1.000{ }^{\circ} \mathrm{C}$, no campo de autoignição do metano.

A maior ocorrência de paralava identificada constitui integralmente a pedreira Rochasul, próximo a Jardim (Mato Grosso do Sul), intrusiva em rochas sedimentares da Bacia do Paraná, cerca de 100-200 m abaixo do contato com o primeiro derrame de basalto. É interpretada como sendo o topo de um complexo estratiforme. Em outras províncias basálticas continentais, como na Groenlândia, há depósitos de Au-EGP-Cu em complexos estratiformes possivelmente gerados por processo de refusão de gabros por queima de metano.

$\mathrm{O}$ evento paralavas $\mathrm{P}$ ocorreu a alta temperatura (1.000-1.800 $\left.{ }^{\circ} \mathrm{C}\right)$ nos basaltos e complexos estratiformes. É interpretado como um processo derrame-a-derrame, causado pela intrusão sequencial de sills de basalto nas formações ricas em material orgânico da Bacia do Paraná. O tempo decorrido entre a intrusão do sill e a refusão de derrame basáltico foi curto, unicamente medido pelo tempo estimado de esfriamento inicial de um derrame espesso (50-80 m) de lava (talvez 1.000 anos).

O sequestro do metano dentro da Bacia do Paraná pelo evento $P$ explica a ausência de extinção significativa de espécies no Cretáceo Inferior. Outras províncias vulcânicas, como a província Sibéria, são comumente consideradas responsáveis pela extinção em massa de espécies. Como a província vulcânica Paraná é a segunda em tamanho em ambientes continentais, a ausência de extinção tem que ser explicada. A queima de carvão não ocorreu em volume significativo, pois a Bacia do Paraná só tem carvão em cerca de $10 \%$ de sua área. No entanto, a geração de metano foi muito significativa no Cretáceo Inferior devido à quebra de querogênio das formações com alto conteúdo orgânico. A introdução desse metano na atmosfera teria, presumivelmente, causado extinção há 135 Ma. Com a identificação do evento de paralavas $\mathrm{P}$, fica identificado o mecanismo de retenção do gás na crosta. A atmosfera permaneceu respirável para plantas e animais.

Os eventos hidrotermais H (Hartmann et al., 2012) são igualmente interpretados como tendo ocorrido derrame -a-derrame, em curto espaço de tempo após o esfriamento da lava a $150{ }^{\circ} \mathrm{C}$ (ainda dentro de 1.000 anos desde a efusão). O panorama inicial é o aquecimento do aquífero Guarani (e outros aquíferos subjacentes) pela intrusão de um sill na bacia sedimentar. Os processos geológicos decorrentes da ascensão (explosiva ou percolante) da água quente e vapor constituem uma singularidade do Grupo Serra Geral, pois as demais províncias continentais não possuem um grande aquífero subjacente. Como a lava possuía uma porosidade de cerca de $30 \%$ após o seu esfriamento, o evento H1 consistiu no preenchimento de todas as cavidades (vesículas e microfraturas) com minerais de alteração, principalmente zeolitas e minerais de argila (esmectita, celadonita). A presença comum de clinoptilolita indica temperatura de cerca de $130^{\circ} \mathrm{C}$ para esse evento. É relevante mencionar que as vesículas de basaltos da Lua e do Havaí permanecem sem preenchimento mineral, devido à ausência de hidrotermalismo.

O evento hidrotermal $\mathrm{H} 2$ foi causado pelo selamento do derrame pelo evento $\mathrm{H} 1$, pois ocorreu aumento da pressão da água quente vapor sob o derrame, até atingir um ponto de soerguimento do derrame (uma placa horizontal). $\mathrm{O}$ arqueamento originou fraturas de vários tipos, inclusive losangulares em três dimensões, no selo, originando a intrusão explosiva do fluido contendo areia fluidizada. O fluido atingiu repetidamente a superfície do derrame, originando extruditos de areia. A fonte da areia foi o erg ativo, situado desde poucos metros até $1.700 \mathrm{~m}$ abaixo do derrame. O fraturamento do selo também pode ter ocorrido devido a terremotos. Após a injeção do fluido, a areia permaneceu como resíduo nas várias estruturas, como diques, sills, stockworks e extruditos. A continuada percolação do fluido quente causou a corrosão dos grãos de quartzo e reprecipitação de calcedônea como cimento. $O$ arenito resultante é uma rocha muito compacta, usada pelo índios para pontas de lanças e flechas.

$\mathrm{O}$ evento hidrotermal $\mathrm{H} 3$ foi gerado pelo novo selamento do derrame pela continuada percolação de fluido quente durante e após o evento H2. A pressão do fluido ficou diminuída em comparação com o H2, pois as moléculas de água percolaram através da crosta inferior e do núcleo maciço do derrame, causando alteração dos minerais ígneos. A pressão interna do fluido só se tornou suficiente para soerguer a porção superior do derrame quando o fluido atingiu 10-20 $\mathrm{m}$ de profundidade abaixo da superfície (Duarte et al., 2009). Nessas condições, ocorreu o soerguimento do derrame; com o alívio da pressão, o fluido explodiu lateralmente em distâncias de 10-20 km, deixando brechas ao longo da fratura. O fluido manteve a fratura horizontal aberta $(10-30 \mathrm{~cm})$, possibilitando o preenchimento por minerais de sílica (calcedônea, quartzo, ametista). Durante o processo explosivo, foram formadas fraturas inclinadas a $40^{\circ}$, com comprimento de $50-200 \mathrm{~cm}$. A continuada percolação dos fluidos quentes no topo dessa fratura ocasionou a continuada alteração do basalto. O comportanto rúptil do basalto evoluiu assim para o comportamento dúctil, que possibilitou a abertura de cavidade no topo da fratura inclinada (o protogeodo). Com a diminuição da temperatura do fluido $\left(40-50{ }^{\circ} \mathrm{C}\right)$ e longa percolação, foram depositados (Juchem, 1999) os valiosos minerais e formados os geodos de ametista (calcita, gipsita). Após isso, o derrame esfriou inteiramente até a temperatura ambiente do deserto.

A extensa fratura horizontal, formada em processo explosivo no H3 e situada 1-2 $\mathrm{m}$ abaixo dos geodos de ametista, pode ser identificada na beira dos morros e 
coxilhas. Em Ametista do Sul, a posição dessa fratura é utilizada pelos mineradores (garimpeiros) para o estabelecimento do piso da galeria a ser aberta. Na beira do morro, o afloramento da fratura constitui a principal fonte de água potável dos agricultores da região. A fratura é, portanto, um excelente aquífero. A fisiografia do pampa permite a localização aproximada da fratura na beira das coxilhas pela presença de árvores. A localização dessa fratura passa a ser um critério preciso de posicionamento de abertura de novas minas.

Sínters de sílica (eventualmente calcita) ainda não foram encontrados no Grupo Serra Geral, mas devem ser abundantes, formados nos extensos campos termais associados com os eventos $\mathrm{H}$.

Os grandes falhamentos $\mathrm{F}$ podem ser observados em imagens de satélite, tem o componente direcional dominante mas um significativo componente vertical também registrado. São em geral falhas secas, sem formação de minerais hidrotermais. Sua origem está associada à abertura do Oceano Atlântico. A observação visual de campo sugere que os derrames de basalto tenham grande extensão lateral, com continuidade física no mesmo nível. O estudo dos distritos mineiros de Ametista do Sul (Rosenstengel \& Hartmann, 2012) e Entre Rios (Hartmann et al., 2013a), com a integração de geologia de campo com geoquímica de rochas e gamaespectrometria, mostrou a presença de blocos de falha com rejeitos verticais de 100-200 m entre morros vizinhos. Há, portanto, forte descontinuidade horizontal dos derrames.

A presença de sílica gossans $G$ no topo de morros e coxilhas do Grupo Serra Geral é uma significativa descoberta geológica para fins de exploração mineral (Pertille et al., 2013; Baggio et al., 2012). A observação de imagens de satélite com controle seletivo de campo indica a presença de sílica gossans no topo da maioria dos morros do grupo vulcânico, em número de muitos milhares. Essa estrutura foi formada pela alteração hidrotermal dos eventos $H$, seguida da alteração intempérica da mineralização. Como o minério mostra a presença de grande volume de argilas expansivas (esmectita), o processo intempérico do minério foi diferente do basalto não-mineralizado. Em decorrência, o solo do sílica gossan permanece saturado em água, impedindo o estabelecimento da Mata Atlântica (clareiras e lagos) e tornando a grama mais verde e com algumas árvores no topo das coxilhas do pampa. O clima permaneceu árido durante todo processo efusivo gerador do grupo vulcânico, pois não há indicações de presença de sedimentos formados em lagos ou rios.

Os pequenos (100-300 m) lagos ou banhados, que registram a presença de sílica gossan e jazida de geodos de ametista ou ágata em baixo, constituem o depocentro de pequenas bacias sedimentares. Essas bacias captam sedimentos somente do topo do morro ou coxilha, constituindo um registro da evolução da vida e da atmosfera desde o início de sua formação. O estudo feito por Gadens -Marcon (2013) indica o tempo (datação ${ }^{14} \mathrm{C}$ ) de cerca de
10.000 anos para a deposição de $1 \mathrm{~m}$ de argila em sílica gossan de Ametista do Sul. Nessa seção estratigráfica, foi registrada a evolução de plantas e demonstrada a variação do clima nesse período de tempo.

A erosão das rochas vulcânicas do Grupo Serra Geral ocorreu de maneira geral pelo recuo de encostas. $\mathrm{O}$ presente estudo demonstra, no entanto, que o recuo de encostas foi substituído pela erosão laminar horizontal sempre que foi alcançada a porção de um morro ou coxilha mineralizada a geodos de ametista. A mineralização de silício também ocasionou um halo de alteração silícica até uma distância média de $60 \mathrm{~m}$ em torno do minério. Com isso, a erosão somente poderá avançar através do recuo de encostas após a erosão laminar horizontal do minério.

\section{As mineralizações}

Cada um dos vários processos geológicos responsáveis pela formação do Grupo Serra Geral também ocasionou a formação de bens minerais de valor econômico. O evento magmático $\mathrm{M}$ pode ter originado depósitos clássicos de metais ( $\mathrm{Cr}, \mathrm{Ni}$, Co) e não será detalhado.

$\mathrm{O}$ evento de paralavas $\mathrm{P}$ foi identificado recentemente e poderá estar relacionado à gênese de depósitos de Au-EGP-Cu, principalmente em corpos intrusivos. Os parâmetros controladores da presença de depósitos são a presença de camadas sedimentares ricas em matéria orgânica na Bacia do Paraná, a presença de espessa sucessão de sills injetados nessas camadas, e um grande volume de rochas gabróicas a $1.000{ }^{\circ} \mathrm{C}$ para serem refundidas. Com isso, o volume maior de paralavas pode levar à geração de depósitos de metais. Nos ambientes de pirometamorfismo, pode haver a formação de jazidas de rubi.

Os eventos hidrotermais ocasionaram a deposição de minerais valiosos. No evento H1, foram depositados minerais de coleção (zeolitas, outros) em amígdalas. Muito importante, no núcleo das amígdalas ocorreu a deposição de cobre nativo (Pinto et al., 2011); cristais também ocorrem ao longo das superfícies da disjunção colunar, que foram os canais alimentadores do preenchimento das vesículas em derrames espessos (30-80 m). Essa disjunção não foi selada pelos eventos $\mathrm{H}$ devido à sua grande espessura. A porção amigdaloidal dos basaltos também tem grande potencial para a rochagem, que é o uso de pó de rocha para a recuperação de solos empobrecidos. No evento H2, foi observada a deposição de pequeno volume de ouro e prata em arenito injetado em basalto de Realeza (Paraná), identificado em análise química de rocha total e confirmado em observação de cristais por microscopia eletrônica de varredura. O evento H3 gerou as grandes jazidas de geodos de ametista e ágata (calcita, gipsita) no Grupo Serra Geral. A sucessiva passagem de água quente e vapor pelos geodos de derrames já frios, na sua trajetória para atingir o derrame 
mais recente, ocasiona a deposição de ametista, calcita ou gipsita sobre os cristais já presentes. Esse processo pode estar ocorrendo até os dias de hoje, pois o aquífero Guarani encontra-se a $60{ }^{\circ} \mathrm{C}$ na região do depocentro da bacia. A presença de grande volume de esmectitas nos sílica gossans do evento $\mathrm{G}$ tornou esses solos mais férteis que aqueles situados nos basaltos não-mineralizados circundantes.

\section{Discussão e conclusões}

A história natural do Grupo Serra Geral abrange uma extensa e diversificada sequência de eventos. Para o seu pleno entendimento, é necessário investigar processos de fusão parcial do manto astenosférico e litosférico, a ascensão de magmas e suas modificações, a residência dos magmas na crosta e o processo final de efusão das lavas na superfície para formar a segunda maior província basáltica continental da Terra. Na trajetória ascendente, os magmas interagem com a crosta de várias maneiras, inclusive através da liberação do calor dos sills e consequente aumento do grau geotérmico na Bacia do Paraná. Uma pequena parte (talvez 10\%) do volume de magma atingiu a superfície, formando o Grupo Serra Geral. A intrusão de grande volume de sills causou efeitos pirometamórficos muito intensos nas camadas ricas em matéria orgânica, principal a Formação Ponta Grossa e a Formação Irati. Dessa forma, processos sedimentares, pirometamórficos e o comportamento do gás metano são incorporados à interpretação. O lento esfriamento (1.000 anos) de derrames espessos de lava possibilitou a entrada do gás metano na porção basal do núcleo maciço de derrames espessos, com a consequente refusão do basalto e geração de paralavas. Esse processo fica muito significativo para a busca de depósitos minerais ( $\mathrm{Au}, \mathrm{EGP}, \mathrm{Cu}$ ) em complexos estratiformes submetidos à queima de metano.

Após o esfriamento dos derrames abaixo de $900{ }^{\circ} \mathrm{C}$, só há registro de eventos geológicos significativos abaixo de $150{ }^{\circ} \mathrm{C}$. A água quente e vapor provenientes do aquífero Guarani causaram a intensa alteração hidrotermal dos basaltos, a injeção de areia e a mineralização de cobre nativo e geodos de ametista e ágata, além de ouro e prata. $\mathrm{O}$ entendimento dos processos hidrotermais é fundamental para uma avaliação adequada da história natural do grupo.

O grupo foi formado em ambiente árido, não sendo encontradas rochas sedimentares fluviais ou lacustres entre os derrames. As camadas de areia presentes entre muitos dos derrames são extruditos de areia, em alguns casos sills. A busca por sínter de sílica (ou calcita) é meritória, pois águas termais e geisers devem ter sido abundantes e numerosos.

O início da investigação dos depósitos argilosos das pequenas bacias sedimentares nos sílica gossans indica uma forte possibilidade de melhor entendimento da evolução da vida e do clima nos últimos 10.000 anos. O estudo de bacias um pouco maiores (com camada atual de água de 1-3 m), que tenham camadas mais espessas de argila, pode expandir amplamente no tempo (1 Ma?) essa observação.

A história natural do Grupo Serra Geral abrange uma grande diversidade de processos, todos de interesse da sociedade. A grande área e a grande espessura do grupo vulcânico estão expondo a necessidade de estudos amplos e intensos dos muitos aspectos envolvidos.

\section{Agradecimentos}

O autor agradece a infraestrutura disponibilizada, o financiamento e a participação de muitas pessoas. A Universidade Federal do Rio Grande do Sul foi essencial para os estudos, assim como a University of Western Australia e a Stuttgart Universität e também o Serviço Geológico do Brasil (CPRM-PA). O apoio financeiro fundamental foi fornecido pela Fundação de Amparo à Pesquisa do Estado do Rio Grande do Sul e pelo Conselho Nacional do Desenvolvimento Científico e Tecnológico, através de vários projetos. Agradeço a participação de vários alunos de doutorado, mestrado e iniciação científica, e de geólogos da CPRM; sem as discussões e estudos, não seria possível atingir o entendimento geológico aqui exposto.

\section{Referências}

Brückmann, M., Hartmann, L.A., Knijnik, D.B., Andrade, R.H.P., Sato, K. 2013. Extended duration of Paraná volcanism 135-119 Ma. Anais do XIV Simpósio Nacional de Estudos Tectônicos, Chapada dos Guimarães. Mato Grosso, res., 1 p.

Baggio, S.B., Hartmann, L.A., Pertille, J., Antunes, L.M. 2012. Silica Gossans in the Serra Geral Group, Paraná Volcanic Province, as guides for the discovery of new hydrothermal deposits of native copper and amethyst geodes. In: V Simpósio Brasileiro de Exploração Mineral - SIMEXMIN, 2012, Ouro Preto, MG. p. 71.

Duarte, L.C., Hartmann, L.A., Vasconcellos, M.A.Z., Medeiros, J.T.N., Theye, T. 2009. Epigenetic formation of amethyst-bearing geodes from Los Catalanes gemological district, Artigas, Uruguay, southern Paraná Magmatic Province. Journal of Volcanology and Geothermal Research 184, 427436.

Duarte, S.K., Hartmann, L.A., Andrade, R.H.P., Rizzotto, G.J., Baggio, S.B., Barbosa, D.K., Simões Neto, J.A. 2012. Sand injectites produced by 
hydrothermal processes in Serra Geral Group, Mato Grosso do Sul, Brazil. Anais do $46^{\circ}$ Congresso Brasileiro de Geologia, Santos, São Paulo, res., 1 p.

Hartmann, L.A., Wildner, W., Duarte, L.C., Duarte, S.K., Pertille, J., Arena, K.R., Martins, L.C., Dias, N.L. 2010. Geochemical and scintillometric characterization and correlation of amethyst geodebearing Paraná lavas from the Quaraí and Los Catalanes districts, Brazil and Uruguay. Geological Magazine 147, 954-970.

Hartmann, L.A., Antunes, L.M., Rosenstengel, L.M. 2013a. Stratigraphy of amethyst geode-bearing lavas and fault-block structures of the Entre Rios mining district, Paraná volcanic province, southern Brazil. Anais da Academia Brasileira de Ciências 86, 187-198.

Hartmann, L.A., Baggio, S.B., Duarte, S.K. 2013b. Decoding geochemical and gamma-spectrometric signatures from lavas and sand injectites at the base of the Paraná volcanic province, Novo Hamburgo, Brazil. International Geology Review 55, 510-524.

Hartmann, L.A., Duarte, L.C., Massonne, H.-J., Michelin, C., Rosenstengel, L.M., Bergmann, M., Theye, T., Pertille, J., Arena, K.R., Duarte, S.K., Pinto, V.M., Barboza, E.G., Rosa, M.L.C.C., Wildner, W. 2012. Sequential opening and filling of cavities forming vesicles, amygdales and giant amethyst geodes in lavas from the southern Paraná volcanic province, Brazil and Uruguay. International Geology Review 54, 1-14.

Janasi, V.A., Freitas, V.A., Heaman, L.H. 2011. The onset of flood basalt volcanism, Northern Paraná Basin, Brazil: A precise U-Pb baddeleyite/zircon age for a Chapecó-type dacite. Earth and Planetary Science Letters 302, 147-153.

Juchem, P.L. 1999. Mineralogia, geologia e gênese dos depósitos de ametista da região do alto Uruguai, Rio Grande do Sul. Tese de Doutorado, Universidade de São Paulo, São Paulo, Brasil, 225 p.

Licht, O.A.B., Arioli, E.E. 2012. Statistic behavior of major and minor elements in basic, intermediate and acidic rocks of the Serra Geral Formation and Arapey Group, Paraná Large Igneous Province, South America. Revista Pesquisas em Geociências (UFRGS) 39, 247-267.

Gadens-Marcon, G.T. 2013. Inferências paleoambientais e paleoclimáticas para o quaternário continental do sul do Brasil baseadas em análises de palinofácies e de geoquímica orgânica de ambientes influenciados por diferentes regimes hidrológicos. Tese de doutorado, Universidade Federal do Rio Grande do Sul, Porto Alegre, Brasil, 262 p.

Mariani, P., Braitenberg, C., Ussami, N. 2013. Explaining the thick crust in Paraná basin, Brazil, with satellite GOCE-gravity observations. Journal of South American Earth Sciences 45, 209-223.

Marsh, B.D. 2013. On some fundamentals of igneous petrology. Contributions to Mineralogy and Petrology 166, 665-690.

Peate, D.W., Hawkesworth, C.J., Mantovani, M.S.M. 1992. Chemical stratigraphy of Paraná lavas (South America): classification of magma types and their spatial distribution. Bulletin of Volcanology 55, 119-139.

Pertille, J., Hartmann, L.A., Duarte, S.K., Arena, K., Rosa, M.L.C.C., Barboza, E.G. 2013. Gossan characterization in the Quaraí and Los Catalanes amethyst geode districts (Brazil and Uruguay), Paraná volcanic province, using rock geochemistry and gamma-spectrometry. Journal of Geochemical Exploration 124, 127-139.

Pinto, V.M., Hartmann, L.A., Santos, J.O.S., McNaughton, N.J., Wildner, W. 2011. Zircon U-Pb geochronology from the Paraná bimodal volcanic province support a brief eruptive cycle at $\sim 135 \mathrm{Ma}$. Chemical Geology 281, 93-102.

Pinto, V.M., Hartmann, L.A., Wildner, W. 2011. Epigenetic hydrothermal origin of native copper and supergene enrichment in the Vista Alegre district, Paraná basaltic province, southernmost Brazil. International Geology Review 53, 1163-1179.

Rocha-Júnior, E.R.V., Puchtel, I.S., Marques, L., Walker, R.J., Machado, F.B., Nardy, A.J.R., Babinski, M., Figueiredo, A.M.G. 2012. Re-Os isotope and highly siderophile element systematics of the Paraná continental flood basalts (Brazil). Earth and Planetary Science Letters 337-338, 164-173.

Rosenstengel, L.M., Hartmann, L.A. 2012. Geochemical stratigraphy of lavas and fault-block structures in the Ametista do Sul geode mining district, Paraná volcanic province, southern Brazil. Ore Geology Reviews 48, 332-348.

Vye-Brown, C., Self, S., Barry, T.L. 2013. Architecture and emplacement of flood basalt flow fields: case studies from the Columbia River Basalt Group, NW USA. Bulletin of Volcanology 75, 697-718. 
Waichel, B.L., Lima, E.F., Lubachesky, R., Sommer, C.A. 2006. Pahoehoe flows from the central Paraná Continental Flood Basalts. Bulletin of Volcanology 68, 599-610.

Wildner, W., Arioli, E.E., Licht, O.A.B., Costa, V.S., Carrilho, J.C., Longo, E.G., Cantarino, S.C., Sander, A., Perrota, M., Filho, C.R.S. 2006. Geologia e Recursos Minerais do Sudoeste do Estado do Paraná. Convênio CPRM/MINEROPAR, Brasília, Distrito Federal, 95 p. 